\title{
A Bibliometric Analysis of Diets and Breast Cancer Research
}

\author{
Manas Kotepui ${ }^{*}$, Sivaporn Wannaiampikul², Chaowanee Chupeerach ${ }^{3}$, Suwit \\ Duangmano $^{4}$
}

\begin{abstract}
Breast cancer is the most common cancer among women worldwide. The primary aim of this work was to provide an in-depth evaluation of research publications in the field of diets and breast cancer. The impact of economic outcome on national academic productivity was also investigated. Data were retrieved using Pubmed for English-language publications. The search included all research for which articles included words relating to "diets and breast cancer". Population and national income data were obtained from publicly available databases. Impact factors for journals were obtained from Journal Citation Reports ${ }^{\circledR}$ (Thomson Scientific). There were 2,396 publications from 60 countries in 384 journals with an impact factor. Among them, 1,652 $(68.94 \%)$ publications were Original articles. The United States had the highest quantity (51\% of total) and highest of mean impact factor $(\mathbf{8 . 8 5 2})$ for publication. Sweden had the highest productivity of publication when adjusted for number of population (6 publications per million population). Publications from the Asian nation increased from $5.3 \%$ in 2006 to $14.6 \%$ in 2012 . The Original article type was also associated with geography $(p<0.001 ; O R=2.183 ; 95 \% \mathrm{CI}=1.526-3.123)$, Asian countries produced more proportion of Original articles $(\mathbf{8 2} \%)$ than those of rest of the world $(67.6 \%)$. Diets and breast cancer-associated research output continues to increase annually worldwide including publications from Asian countries. Although the United States produced the most publications, European nations per capita were higher in publication output.
\end{abstract}

Keywords: Diets - breast cancer - publications - country distribution - impact factor

Asian Pac J Cancer Prev, 15 (18), 7625-7628

\section{Introduction}

Medical progress on scientific communication continues to increase annually. The scientific publication has increased due to the information explosion. Bibliometric studies are increasingly being used for research assessment by involving the application of statistical methods to obtain the bibliographics for topic of researcher's interest. These methods are mainly quantitative but are also used to make pronouncements about qualitative pictures of scientific activities around the world (Zyoud et al., 2014). Well-known databases for bibliographics analysis are PubMed, Scopus, Web of Science [i.e., Thomson Reuters Institute for Scientific Information (ISI)], and Google Scholar index international publications in biomedical sciences (Falagas et al., 2008).

PubMed is a database developed by the National Center for Biotechnology Information (NCBI) at the National Library of Medicine (NLM), one of the institutes of the National Institutes of Health (NIH). The database was designed to provide access to citations from biomedical journals which include both Medline and non-Medline databases (http://www.ncbi.nlm.nih.gov/pubmed). They were many bibliometric researches in the field of oncology (Ugolini and Mela, 2003; Ugolini et al., 2007; Michon and Tummers, 2009; Chua et al., 2011). However, few studies have documented patterns of publications in clinical and basic science research involving breast cancer research output (Glynn et al., 2010; Perez-Santos and Anaya-Ruiz, 2013).

Breast cancer is the most common cancer among women in the world with an estimated 1.67 million new cancer cases diagnosed in 2012 accounting for $25 \%$ of all cancers and also ranks as the fifth cause of death from cancer overall (522,000 deaths) (Ferlay et al., 2013). In Asia, breast cancer has also been reported as the most common cancer among women and the second leading cause of death (12.8\% of all cancer) (Ferlay et al., 2013). The role of diets is implicated in incidence of breast cancer (Parry et al., 2011). There was some evidences that the dietary intake of subjects in developing countries needs improvement such as fat intake should be changed to

${ }^{1}$ Department of Medical Technology Program, School of Allied Health Sciences and Public Health, Walailak University, ${ }^{3}$ Institute of Nutrition, Mahidol University, Nakhon Pathom, ${ }^{2}$ Department of Tropical Nutrition and Food Science, Faculty of Tropical Medicine, Mahidol University, Bangkok, ${ }^{4}$ Department of Medical Technology, Faculty of Associated Medical Sciences, Chiang Mai University, Chiang Mai, Thailand *For correspondence: manas.ko@wu.ac.th 


\section{Manas Kotepui et al}

reduce risk of developing breast cancer (Esmaillzadeh and Azadbakht, 2008). To affirm conclusions about diets and breast cancer, researchers would have to find association between those. The primary aim of this present work was to provide an in-depth evaluation of research publications in the field of diets and breast cancer using Pubmed, and other publicly available databases, and also examined global research productivity and trends in Asian countries.

\section{Materials and Methods}

Data of publications were gathered using Pubmed database. The search terms using a combination of "diet and breast cancer" was used to extract English language publications. The impact factors for publications in 2012 were retrieved from Journal Citation Reports (Thomson Scientific). Citations were imported into the EndNote ${ }^{\circledR}$ bibliographic management software (Thomson Scientific). Review articles, Case reports, Letters to the editor and etc. were retrieved and categorized to spreadsheet. Country labels were individually collected from the "author address" field in EndNote for each publication. Publications from Northern Ireland, England, Scotland, and Wales were grouped as United Kingdom. Publications from Hong Kong were not grouped with China because there were different quantitative variables for the two regions. Country-specific data and income category were gathered from the World Bank List of Economies (http:// data.worldbank.org/country). Briefly, 266 countries are classified by the World Bank according to 2012 Gross National Income per capita as Low income ( $\$ 875$ or less), Lower middle income $(\$ 876-\$ 3,465)$, Upper middle income $(\$ 3,466-\$ 10,725)$, and High income $(\$ 10,726)$. A complete description of this methodology and countries included is available on the World Bank website (http:// data.worldbank.org/country). The data were then analyzed using SPSS statistical software version 11.5 statistical package with cross tabulations between individual databases and differences were considered statistically significant at $\mathrm{p}<0.05$.

\section{Results}

The results showed that there were 2,396 research publications produced from 1994 to 2012. The number of publication was increased over the timeline (Figure 1 ). These publications were represented by authors from 60 countries. Among the 60 countries represented in the database, 24 had 10 or more publications (Table 1 ). These countries accounted for 2,278 of the total 2,396 publications (95\%). The United States had the highest 1,243 publications $(52 \%)$, whereas publication from Asia counties contributed 217 publications (9\%). Original articles constituted a majority of the publications $(1,652$ of 2,$396 ; 69 \%)$. Whereas Review article were next at $24 \%$, followed by Letters to the editor (2\%) (Table 2). The country with the highest number of Original article was United States 844 (67.9\%), followed by Canada 112 (77.2\%) and Italy 77 (68.1\%). Impact factor information was available for 384 journals from the Journal Citation Reports. The mean impact factor for all publications
Table 1. Country Representation

\begin{tabular}{lccccc}
\hline Country & $\begin{array}{c}\text { Publica- } \\
\text { tions }\end{array}$ & $\begin{array}{c}\text { Population } \\
\text { (millions) }\end{array}$ & $\begin{array}{c}\text { Publications } \\
\text { per millions }\end{array}$ & $\begin{array}{c}\text { Mean } \\
\text { IF }\end{array}$ & $\begin{array}{c}\text { Income } \\
\text { categories }\end{array}$ \\
\hline USA & 1243 & 314 & 3.95 & 5.85 & High \\
Canada & 145 & 34.9 & 4.15 & 4.86 & High \\
UK & 145 & 63.2 & 2.29 & 4.84 & High \\
Italy & 113 & 60.9 & 1.85 & 4.36 & High \\
France & 77 & 65.7 & 1.17 & 2.93 & High \\
Japan & 62 & 128 & 0.48 & 3.19 & High \\
Sweden & 58 & 9.52 & 6.09 & 5.63 & High \\
Spain & 51 & 46.2 & 1.1 & 3.15 & High \\
Germany & 45 & 81.9 & 0.54 & 4.28 & High \\
Australia & 41 & 22.7 & 1.8 & 4.77 & High \\
China & 41 & 1350 & 0.03 & 2.41 & Upper middle \\
Netherlands & 39 & 16.8 & 2.32 & 5.35 & High \\
Denmark & 32 & 5.59 & 5.72 & 4.97 & High \\
Finland & 32 & 5.41 & 5.91 & 4.24 & High \\
Korea & 32 & 50 & 0.64 & 2.77 & High \\
India & 19 & 1240 & 0.01 & 2.31 & Lower middle \\
Greece & 18 & 11.3 & 1.59 & 3.32 & High \\
Mexico & 17 & 121 & 0.14 & 2.49 & Upper middle \\
Israel & 13 & 7.91 & 1.64 & 1.86 & High \\
Norway & 13 & 5.02 & 2.59 & 3.95 & High \\
Hong Kong & 11 & 7.16 & 1.53 & 3.52 & High \\
Taiwan & 11 & 23.3 & 0.47 & 3.03 & High \\
Brazil & 10 & 199 & 0.05 & 1.6 & Upper middle \\
Malaysia & 10 & 29.2 & 0.34 & 1.37 & High \\
*IF=Impact factor & & & &
\end{tabular}

\section{Table 2. Types of Articles}

\begin{tabular}{lcc}
\hline Article type & Frequency & $\%$ \\
\hline Original article & 1652 & 68.9 \\
Review articles & 563 & 23.5 \\
Letters to the editor & 46 & 1.9 \\
Meta-analyses & 34 & 1.4 \\
Editorial & 31 & 1.3 \\
Case reports & 9 & 0.4 \\
Book & 2 & 0.1 \\
Miscellaneous & 59 & 2.5 \\
Total & 2396 & 100 \\
\hline
\end{tabular}

Table 3. Countries and Types of Research Publications

\begin{tabular}{|c|c|c|c|c|c|}
\hline \multirow[t]{2}{*}{ Type of publication } & \multicolumn{2}{|c|}{ Countries } & \multirow[t]{2}{*}{ P-value* } & \multirow[t]{2}{*}{ Odds ratio } & \multirow[t]{2}{*}{$95 \% \mathrm{CI}^{* *}$} \\
\hline & Asian & Non-Asian & & & \\
\hline Research articles & $178(82)$ & $1474(67.6)$ & $<0.01$ & 2.18 & $1.52-3.12$ \\
\hline $\begin{array}{l}\text { Non- research } \\
\text { articles }\end{array}$ & 39 (18) & $705(32.4)$ & & & \\
\hline Total & 217 (100) & $2179(100)$ & & & \\
\hline
\end{tabular}

was 4.63. Among the 24 countries with more than 10 publications, publications from United States had the highest mean impact factor (5.85). Most of the research publication was produced from High income country (41 of $60 ; 68 \%$ ). Upper middle income were next at $24 \%$, followed by Lower middle income (8\%) (Figure 2).

The Asia countries produced low (217 of 2,396; $9 \%$ ) publications each year when compared with global publications. However, publications from the Asia countries continues to increased annually from $6.5 \%$ in 2005 to $14.6 \%$ in 2012 in the last seven year same as the global trend. Sweden had the most publications per capita, which was 6 publications per million people. Among the top 24 countries with 10 or more publications, the 24 high income countries published a median of 1.6 manuscripts per million people (range 0.02 [India] to 6.1 [Sweden]). 


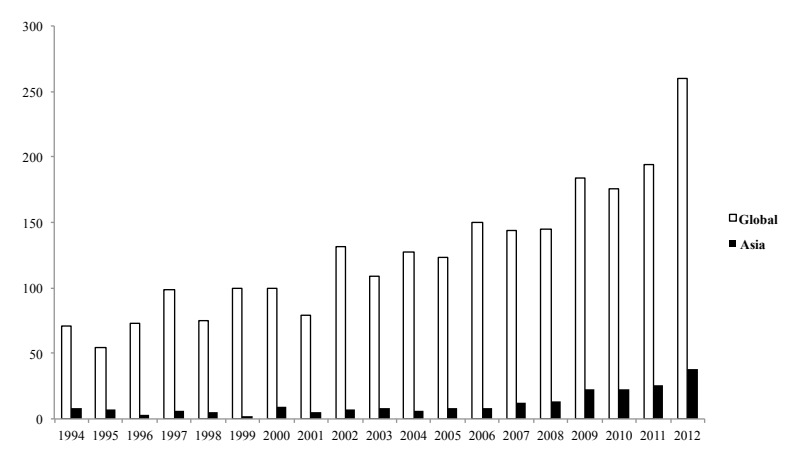

Figure 1. Research Publications Produced from 1994 to 2012

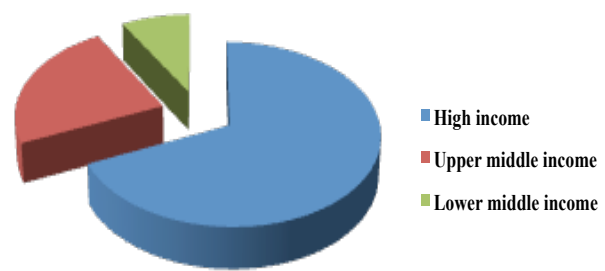

Figure 2. Research Publication was Produced from High Income Country, Upper Middle, Followed by Lower Middle Income

The 19 countries not classified as high income nations published a median of 1.0 manuscripts per million people (range 0.01 [Nigeria, Pakistan] to 2.7 [Uruguay]). Original articles was associated with countries distribution (Pearson Chi-Square $=19.07, \mathrm{df}=1, \mathrm{p}<0.01 ; \mathrm{OR}=2.18$ ) (Table 3). Asian countries produced more proportion of Original article $(82 \%)$ than those of non-Asian countries $(67.6 \%)$.

\section{Discussion}

An increase in the publication of scientific literature indicates the speed of progress of science and technology. The current study found that the number of diets and breast cancer articles published totally increased between 1994 and 2012, indicating an important rapid development in the field of diets and breast cancer. The United States had the most number of article publications. Although the overall productivity of research publication was highest for the United States, but per capita productivity was higher in Western European countries such of Sweden. It can be caused by economic development which had a significant impact on research productivity, with higher income nations likes the United States contributing to a majority of publications which supported by the previous studies (Glynn et al., 2010; Perez-Santos et al., 2013).

The United States and Western Europe had the highest mean impact factor of their publications when compared with other parts of the world, which likely reflects the relatively high research citations. An influence of journals'countries of origin and the languages used may influence higher impact factor such as journals originating in North America tend to have a higher impact factor, followed by journals from Northern and Western Europe (Karageorgopoulos et al., 2011). A greater share of articles in English might improves international recognitions and Result in higher impact factor.
This analysis has also demonstrated the leading role which the United States plays in breast cancer research, a finding previously noted in other scientific disciplines amount of money spent on the management of breast cancer. Although research publication was increasingly year by year, there was an annually the dramatic underrepresentation of article publication from South America, Africa, and to a lesser extent, Asia (van Rossum et al., 2007; Klar et al., 2009). A publication produced from Asian countries was relatively low and might be the results of the low level of annual spending on Research and Development (R\&D) such as in Arab states which is just $0.2 \%$ of the gross national product compared to the world average of $1.4 \%$ and moreover, majority of researchers and scientists from other Asian countries is also immigrating to other countries which may creates a gap between Asian publications and global publications (McKee etal., 2012). The countries responsible for most publications in Asian countries were Japan, China, Korea, India, Israel, Hong Kong, Taiwan, and Malaysia. This may due to the fact that they spending more on $R \& D$ and generating more in research outcomes (Meo et al., 2013). Moreover, authors from Asian countries might be more likely to publish non-English articles to choose his native language for publication (Diekhoff et al., 2013).

This study, Low and Middle income countries produced low number of research publication. Several potential reasons is among Low-and Middle-income countries were limited governmental or non-governmental funding, lack of health research strategy, lack of political that engage health research, or ongoing conflict (McKee et al., 2012). Countries categorized by the World Bank as "High income" dominated research productivity, consistent with previous reports linking economic development with scientific output (Monge-Najera and Nielsen, 2005; Michalopoulos and Falagas, 2005; Rosmarakis et al., 2005). In this study dealing with diets and breast cancer, suggesting a growing interest in diets and breast cancer research worldwide including Asian countries as shown by the increased number of publications each year especially during the last 7 years. Breast cancer as a specialty interacts with many disciplines. This enables scientists in the field of nutrition can collaborate in breast cancer research. Consequently, the opportunities for publication extend to a broad range of journals. A previous metaanalysis has shown the influence of diets as a modifiable risk factor on breast cancer risk, and it is estimated that approximately one-third of cases could be prevented by dietary modification (Brennan et al., 2010).

This study has several limitations related to the search methodology and databases used. This study included only English-language publications because English is the language with the widest readership and global reach (Villar, 1988). This study also included publications only from 1994 onwards, when electronic submissions in major journals made it easier to track author affiliations. This study can concluded that breast cancer research in Asian is still developing. The findings of this study should provide useful information for those who will be performing research and studying diets and breast cancer. Although the United States leads in academic productivity, a European 


\section{Manas Kotepui et al}

nation is higher in scientific output per capita. Economic development is closely linked to national research productivity with high income nations dominating global research publications.

\section{References}

Brennan SF, Cantwell MM, Cardwell CR, Velentzis LS, Woodside JV (2010). Dietary patterns and breast cancer risk: a systematic review and meta-analysis. Am J Clin Nutr, 91, 1294-302.

Chua TC, Crowe PJ, Morris DL (2011). Trends in surgical oncology research in Australia during the period 1998-2009-a bibliometric review. J Surg Oncol, 104, 216-9.

Diekhoff T, Schlattmann P, Dewey M (2013). Impact of article language in multi-language medical journals--a bibliometric analysis of self-citations and impact factor. PLoS One, $\mathbf{8}$, 76816.

Esmaillzadeh A, Azadbakht L (2008). Consumption of hydrogenated versus nonhydrogenated vegetable oils and risk of insulin resistance and the metabolic syndrome among Iranian adult women. Diabetes Care, 31, 223-6.

Falagas ME, Pitsouni EI, Malietzis GA, Pappas G (2008): Comparison of pubmed, scopus, web of science, and google scholar: strengths and weaknesses. FASEB J, 22, 338-42.

Ferlay J, Steliarova-Foucher E, Lortet-Tieulent J, et al (2013). Cancer incidence and mortality patterns in Europe: estimates for 40 countries in 2012. Eur J Cancer, 49, 1374-403.

Glynn RW, Scutaru C, Kerin MJ, Sweeney KJ (2010). Breast cancer research output, 1945-2008: a bibliometric and density-equalizing analysis. Breast Cancer Res, 12, 108.

Karageorgopoulos DE, Lamnatou V, Sardi TA, Gkegkes ID, Falagas ME (2011). Temporal trends in the impact factor of European versus USA biomedical journals. PLoS One, 6, 16300 .

Klar M, Foldi M, Denschlag D, Stickeler E, Gitsch G (2009). Estimates of global research productivity in gynecologic oncology. Int J Gynecol Cancer, 19, 489-93.

McKee M, Stuckler D, Basu S (2012). Where there is no health research: what can be done to fill the global gaps in health research? PLoS Med, 9, 1001209.

Meo SA, Al Masri AA, Usmani AM, Memon AN, Zaidi SZ (2013). Impact of GDP, spending on R\&D, number of universities and scientific journals on research publications among Asian countries. PLoS One, 8, 66449.

Michalopoulos A, Falagas ME (2005). A bibliometric analysis of global research production in respiratory medicine. Chest, 128, 3993-8.

Michon F, Tummers M (2009). The dynamic interest in topics within the biomedical scientific community. PLoS One, 4, 6544.

Monge-Najera J, Nielsen V (2005). The countries and languages that dominate biological research at the beginning of the $21^{\text {st }}$ century. Rev Biol Trop, 53, 283-94.

Parry BM, Milne JM, Yadegarfar G, Rainsbury RM (2011). Dramatic dietary fat reduction is feasible for breast cancer patients: Results of the randomised study, WINS (UK)-stage 1. Eur J Surg Oncol, 37, 848-55.

Perez-Santos JL, Anaya-Ruiz M (2013). Mexican breast cancer research output, 2003-2012. Asian Pac J Cancer Prev, 14, 5921-3.

Rosmarakis ES, Vergidis PI, Soteriades ES, et al (2005). Estimates of global production in cardiovascular diseases research. Int J Cardiol, 100, 443-9.

Ugolini D, Mela GS (2003). Oncological research overview in the European Union. A 5-year survey. Eur J Cancer, 39, 1888-94.
Ugolini D, Puntoni R, Perera FP, Schulte PA, Bonassi S (2007). A bibliometric analysis of scientific production in cancer molecular epidemiology. Carcinogenesis, 28, 1774-9.

Van Rossum M, Bosker BH, Pierik EG, Verheyen CC (2007). Geographic origin of publications in surgical journals. $\mathrm{Br}$ J Surg, 94, 244-7.

Villar J (1988). English, an international language in medicine. Med Clin, 91, 23-4.

Zyoud SH, Al-Jabi SW, Sweileh WM, Awang R (2014). A bibliometric analysis of toxicology research productivity in Middle Eastern Arab countries during a 10-year period (2003-2012). Health Res Policy Syst, 12, 4. 